\title{
ETNOBOTANI PAKAIAN ADAT DALAM KEGIATAN RITUAL MASYARAKAT ETNIS DAYAK KANAYATN DI KALIMANTAN BARAT
}

\author{
Roberto $^{1}$ *, Rafdinal ${ }^{1}$, Elvi Rusmiyanto P. W. ${ }^{1}$ \\ ${ }^{1}$ Jurusan Biologi, Fakultas Matematika dan Ilmu Pengetahuan Alam, Universitas Tanjungpura, Pontianak \\ *Email korespondensi: c.567berto@gmail.com
}

\begin{abstract}
Dayak Kanayatn as one of the Dayak ethnic in Kalimantan Barat has a tendency to use its natural resource such as plants to support various tradition costum needs, such as tradition clothing which are absolute within the traditional costum ritual. The purpose of this research is to find out the species of plants and its parts that used as material in the Dayak Kanayatn traditional costum clothing. The research was conducted between April until July 2019. The result of the research found that there are 24 species of plants from 12 family. The most used family are the Arecaceae ( 8 species), Poaceae ( 5 species), and Moraceae ( 2 species). Parts of the plants which used the most are branch (44\%), then skin of the branch (26\%), and the wood (13\%). All the plants which are used had its own specific meaning for Dayak Kanayatn people.
\end{abstract}

Keywords: Dayak Kanayatn Ethnic, Rituals, Traditional Costum Clothing, West Kalimantan

\section{PENDAHULUAN}

Suku Dayak adalah salah satu suku yang tersebar di seluruh wilayah provinsi Kalimantan Barat. Suku Dayak terdiri atas 151 etnis (sub suku), serta terbagi dalam 168 variasi bahasa (Alloy et.al., 2008). Menurut Miden (2014), Dayak Kanayatn adalah salah satu etnis Dayak yang memiliki penyebaran bahasa terluas di Kalimantan Barat.

Setiap kebudayaan, adat istiadat dan pengetahuan lokal masyarakat Dayak disusun oleh berbagai unsur alam (Darmadi, 2016). Menurut Florus et.al. (2014), Dayak Kanayatn adalah salah satu etnis Dayak yang memiliki interaksi erat dengan alam dalam berbagai aspek kehidupan. Upacara dan aktivitas religi Dayak Kanayatn selalu dilaksanakan di sekitar pohon besar, gunung, sungai dan hutan yang melambangkan keagungan Tuhan (Jubata).

Adat Dayak Kanayatn adalah bentuk regulasi kehidupan masyarakat Dayak Kanayatn terhadap alam. Adat mengatur perilaku masyarakat dalam pekerjaan tahunan, mata pencaharian, tradisi perkabungan, pelanggaran adat, serta petunjuk, teguran dan larangan sosial untuk tujuan kebaikan manusia dan alam (Andasputra \& Julipin, 1997). Pelaksanaan kegiatan adat Dayak Kanayatn terikat dengan beberapa komponen mutlak yaitu pakaian, makanan (persembahan) dan nyangahatn (doa).

Menurut Jalung (2015), pakaian adat merupakan komponen dasar adat istiadat dan menjadi ciri khas setiap etnis Dayak. Pakaian adat dapat mengilustrasikan kondisi sosial masyarakat dan merupakan ekspresi sebuah ritual yang unik. Menurut Darmadi (2016), pakaian adalah lambang kehormatan dan status sosial seorang Dayak selain mandau dan tato.

Tumbuhan adalah komponen penyusun hutan yang banyak digunakan masyarakat adat sebagai obatobatan, kosmetik, makanan, pewarna, pakaian dan bahan upacara tradisional (Syafitri, et.al., 2014). Beberapa pemanfaatan tumbuhan oleh masyarakat Dayak yang telah terpublikasi secara ilmiah antara lain sebagai bahan obat, kosmetik dan pewarna. Menurut Andasputra dan Julipin (1997), pemanfaatan tumbuhan oleh masyarakat etnis Dayak Kanayatn sebagai bahan pakaian adat belum banyak dipublikasikan secara ilmiah. Sehingga, penelitian ini penting untuk dilaksanakan. Tujuan dari penelitian ini adalah untuk mengetahui jenis tumbuhan yang digunakan sebagai bahan dalam pembuatan pakaian adat oleh masyarakat Dayak Kanayatn dan mengetahui bagian tumbuhan yang digunakan.

\section{BAHAN DAN METODE}

\section{Waktu dan Tempat Penelitian}

Penelitian ini dilaksanakan selama 4 bulan yaitu pada bulan April sampai Juli 2019. Pengambilan data penelitian dilaksanakan di daerah domisili 
pengrajin pakaian adat Dayak Kanayatn. Pengambilan sampel tumbuhan dilaksanakan di hutan atau daerah sekitar domisili pengrajin pakaian adat. Identifikasi dan pengolahan data hasil penelitian dilaksanakan di Laboratorium Bio-logi dan Ruang Baca Program Studi Biologi, Fakultas Matematika dan Ilmu Pengetahuan Alam, Universitas Tanjungpura, Pontianak.

\section{Deskripsi Lokasi Penelitian}

Lokasi penelitian terdiri atas:

1. Desa Dharma Bhakti Kecamatan Teriak, Desa Bumi Emas Kota Bengkayang dan Desa Terap Kecamatan Menjalin (Daerah domisili Dayak Kanayatn Banana'-Ahe)

2. Desa Marunsu Kecamatan Samalantan (Daerah domisili Dayak Kanayatn Badamea-Jare)

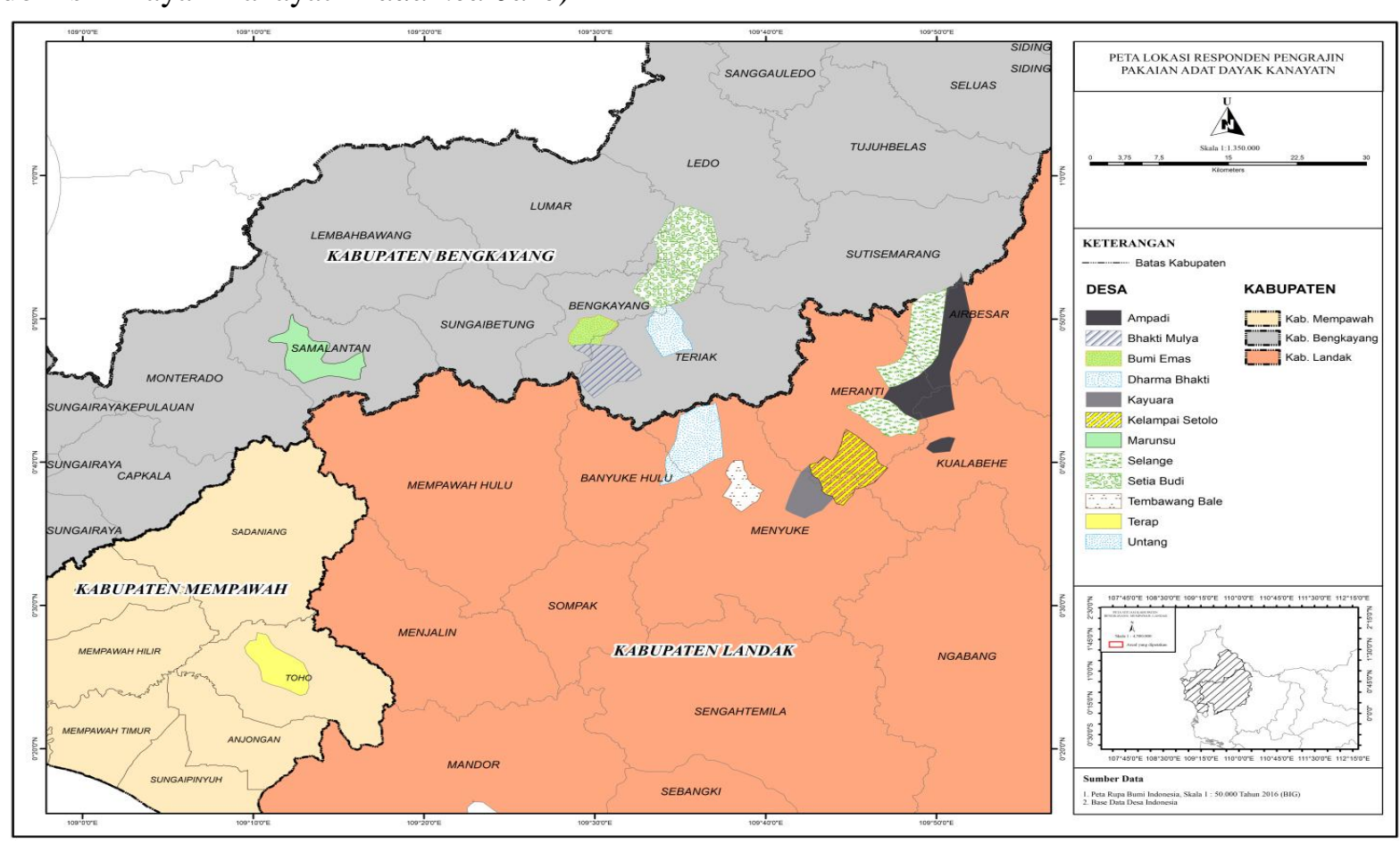

Gambar 1. Peta Lokasi Responden Pengrajin Pakaian Adat Dayak Kanayatn

\section{Pelaksanaan Penelitian}

Responden ditentukan menggunakan metode purposive sampling dengan kriteria memiliki pengetahuan dan/atau keterampilan membuat, serta mencari bahan pakaian adat dari tumbuhan. Responden terdiri atas perwakilan enam bahasa pada etnis Dayak Kanayatn yaitu:

1. Banana'-Ahe

2. Badamea-Jare

3. Baampape

4. Bakati'

5. Banyadu' \&

6. Bakambai
3. Desa Kayuara Kecamatan Menyuke dan Desa Kelampai Setolo Kecamatan Meranti (Daerah domisili Dayak Kanayatn Baampape)

4. Desa Bhakti Mulya Kecamatan Teriak dan Desa Setia Budi Kecamatan Sebalo (Daerah domisili Dayak Kanayatn Bakati')

5. Desa Untang dan Desa Tembawang Bale Kecamatan Banyuke Hulu (Daerah domisili Dayak Kanayatn Banyadu')

6. Desa Ampadi dan Desa Selange Kecamatan Meranti (Daerah domisili Dayak Kanayatn Bakambai).

Penentuan tempat penelitian didasarkan pada penggunaan bahasa dominan pada daerah tersebut. Responden mewakili 6 bahasa pada etnis Dayak Kanayatn. 
(Susilo et.al., 2014), buku Taksonomi Umum Dasar-Dasar Taksonomi Tumbuhan (Gembong, 1998), buku identi-fikasi Malesian Seed Plants Vol. I \& II (Van Balgooy, 1997 \& 1998), serta Database Plants Of The World Online (www.plantsoftheworldonline.org). Data hasil penelitian dianalisis secara deskriptif menggunakan tabel dan grafik.

\section{HASIL DAN PEMBAHASAN}

\section{Hasil}

Hasil penelitian diperoleh sebanyak 24 spesies tumbuhan yang digunakan sebagai bahan pakaian adat. Dua puluh empat spesies tumbuhan terdiri dari 12 famili dan tergolong dalam 16 genus. Informasi lengkap dapat dilihat dalam Tabel 1.

Tabel 1. Jenis-Jenis Tumbuhan yang dimanfaatkan sebagai Bahan Pakaian Adat

\begin{tabular}{|c|c|c|c|c|}
\hline \multirow[t]{2}{*}{ No. } & \multirow[t]{2}{*}{ Famili } & \multicolumn{2}{|c|}{ Spesies Tumbuhan yang Dimanfaatkan } & \multirow{2}{*}{$\begin{array}{l}\text { Bagian Tumbuhan } \\
\text { yang Diambil }\end{array}$} \\
\hline & & Nama Ilmiah & Nama Lokal & \\
\hline 1 & 2 & 3 & 4 & 5 \\
\hline \multirow[t]{8}{*}{1} & Arecaceae & Calamus $\mathrm{sp}_{1}$ & Oe Maro & Batang \\
\hline & & Calamus $\mathrm{sp}_{2}$ & Oe Palades & Batang \\
\hline & & Calamus $\mathrm{sp}_{3}$ & Oe Jerayatn & Batang \\
\hline & & Calamus erioachanthus Becc. & Oe Saga & Batang \\
\hline & & Calamus tetrastichus Blume & Rotan Lilin & Batang \\
\hline & & Korthalsia rigida Blume & Rotan Cabang & Batang \\
\hline & & Korthalsia echinometra Becc. & Rotan Udang & Batang \\
\hline & & Metroxylon sagu Rottb. & Sagu & Pelepah \\
\hline \multirow[t]{6}{*}{2} & Poaceae & Bambusa maculata Widjaja & Bambu Tutul & Kulit batang \\
\hline & & Bambusa balcooa Roxb. & Bambu Balku & Kulit batang \\
\hline & & Schizostachyum $\mathrm{sp}_{1}$ & Bambu Munti & Batang \\
\hline & & $\begin{array}{l}\text { Schizostachyum brachycladum } \\
\text { (Kurz ex Munro) Kurz }\end{array}$ & Bambu Talang & Kulit batang \\
\hline & & Schizostachyum lima (Blanco) & Bambu Lengis & Kulit batang \\
\hline & & Merr. & & \\
\hline \multirow[t]{2}{*}{3} & Moraceae & $\begin{array}{l}\text { Artocarpus elasticus Reinw. ex } \\
\text { Blume }\end{array}$ & Terap & Kulit batang \\
\hline & & Ficus racemosa $\mathrm{L}$. & Loa & Kayu \\
\hline 4 & Gleicheniaceae & $\begin{array}{l}\text { Dicranopteris linearis (Burm.f.) } \\
\text { Underw. }\end{array}$ & Resam & $\begin{array}{l}\text { Empulur batang \& } \\
\text { Batang }\end{array}$ \\
\hline 5 & Apocynaceae & Alstonia scholaris (L.) R.Br. & Pulai & Kayu \\
\hline 6 & Pandanaceae & Pandanus sp. & Pandan duri & Daun \\
\hline 7 & Fagaceae & $\begin{array}{l}\text { Lithocarpus cantleyanus (King } \\
\text { ex Hook.f.) Rehder }\end{array}$ & Mampaning & Buah \\
\hline 8 & Thymelaeaceae & Aquilaria microcarpa Baill. & Gaharu & Kayu \\
\hline 9 & Marantaceae & $\begin{array}{l}\text { Donax canniformis (G.Forst.) } \\
\text { K.Schum. }\end{array}$ & Bemban & Kulit batang \\
\hline 10 & Asparagaceae & $\begin{array}{l}\text { Cordyline fruticosa (L.) } \\
\text { A.Chev. }\end{array}$ & Sabang merah & Daun \\
\hline 11 & Flagellariaceae & Flagellaria indica L. & Rotan tikus & Batang \\
\hline 12 & Melastomataceae & Melastoma malabathricum L. & Senduduk & Batang \\
\hline
\end{tabular}

Berdasarkan jumlah spesies yang dimanfaatkan dalam satu famili, persentase pemanfaatan tumbuhan sebagai bahan pakaian adat yang memiliki nilai paling besar adalah famili Arecaceae (33,33\%), kemudian famili Poaceae $(20,83 \%)$ dan famili Moraceae (8,33\%). Famili Gleicheniaceae, Apocynaceae, Pandanaceae, Fagaceae, Thymelaeaceae, Marantaceae, Asparagaceae, Flagellariaceae dan Melastomataceae masing-masing memiliki persentase pemanfaatan sebesar $4,17 \%$ (lihat Gambar 2.).

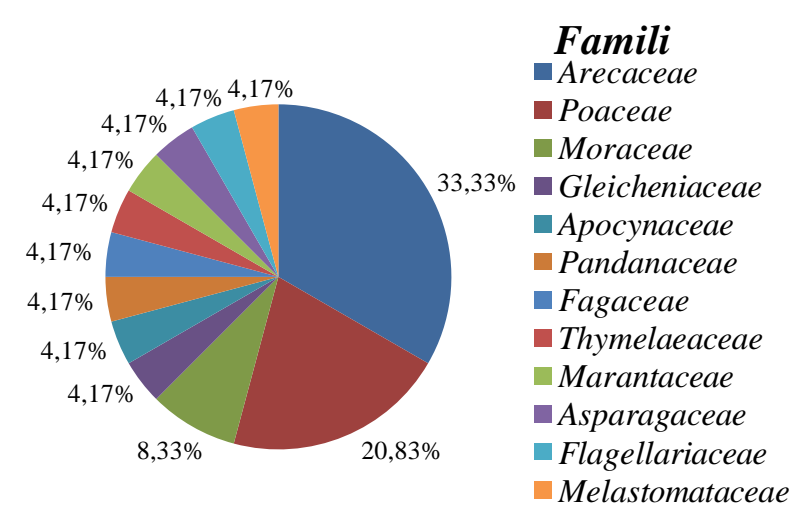

Gambar 2. Grafik Nilai Pemanfaatan Tumbuhan berdasarkan Jumlah Spesies dari Setiap Famili. 
Persentase pemanfaatan tumbuhan berdasarkan bagian tumbuhan yang dimanfaatkan pada semua spesies menunjukan bahwa bagian tumbuhan dengan persentase terbesar adalah batang (44\%), kemudian bagian kulit batang (26\%), bagian kayu $(13 \%)$, serta bagian empulur batang, pelepah, daun dan buah tumbuhan digunakan paling rendah yaitu 4\% (lihat Gambar 3.).

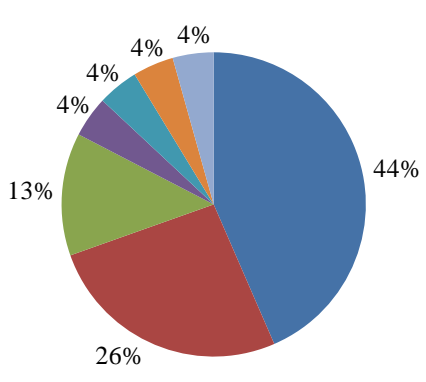

Bagian Tumbuhan
Batang
Kulit batang
Kayu
Empulur batang
Pelepah
Daun
Buah

Gambar 3. Grafik Nilai Pemanfaatan Bagian-Bagian Tumbuhan sebagai Bahan Pakaian Adat.

\section{Pembahasan}

Berdasarkan hasil penelitian diperoleh 24 spesies tumbuhan yang dimanfaatkan sebagai bahan pakaian adat oleh masyarakat Dayak Kanayatn (Tabel 1.). Jumlah ini lebih banyak dari masyarakat sub-etnis Batak Toba di Desa Martoba, Kabupaten Samosir, Provinsi Sumatera Utara yang memanfaatkan 4 spesies tumbuhan sebagai bahan pakaian (Ibo \& Arimukti, 2019). Kemudian lebih banyak dari jumlah pemanfaatan oleh masyarakat Desa Sukolilo, kawasan pegunungan Kendeng Pati, Provinsi Jawa Tengah yang memanfaatkan 11 jenis tumbuhan sebagai bahan yang berpotensi sebagai bahan pakaian tradisional (Irsyad et.al (2013), serta lebih banyak dari pemanfaatan oleh suku Melayu di sekitar Taman Nasional Bukit Tigapuluh Provinsi Riau yang memanfaatkan 21 spesies tumbuhan sebagai bahan berpotensi pakaian (Fakhrozi, 2009). Menurut Iswandono et.al. (2015), di Pegunungan Ruteng Provinsi Nusa Tenggara Timur masyarakat suku Manggarai memanfaatkan lebih banyak tumbuhan sebagai bahan pakaian yaitu sebanyak 34 spesies.

Selain itu, bahan pakaian dan kerajinan salah satu etnis Dayak yaitu masyarakat Dayak Iban-Desa di Kabupaten Sintang terdiri atas 19 spesies tumbuhan, 3 varietas tumbuhan dan 1 sub varietas tumbuhan yang secara keseluruhan tergolong dalam 4 famili tumbuhan (Dewi, 2016). Masyarakat suku Melayu Kabupaten Landak Provinsi Kalimantan Barat menurut Hasanah et.al. (2014), hanya memanfaatkan 1 spesies tumbuhan sebagai bahan gantungan atau tali dalam ritual adat Tumpang Negeri.
Pemanfaatan tumbuhan sebagai bahan pakaian antara etnis Melayu Kabupaten Landak dan etnis Dayak Iban-Desa Kabupaten Sintang terhadap etnis Dayak Kanayatn yang berada dalam provinsi yang sama memiliki beberapa perbedaan. Perbedaan signifikan terdapat pada etnis Melayu dan Dayak Kanayatn, sedangkan antara Dayak Kanayatn dan Dayak Iban-Desa hampir sama dalam jenis-jenis famili tumbuhan dan jumlah tumbuhan. Menurut Suryadarma (2008), variasi jenis tumbuhan yang dimanfaatkan antar suatu etnis disebabkan oleh perbedaan kebudayaan, karena setiap etnis memiliki nilai-nilai pengetahuan dan pandangan terhadap tumbuhan. Faktor lingkungan (habitat tumbuhan) dan keanekaragaman tumbuhan juga mempengaruhi pola pemanfaatan suatu etnis.

Variasi pemanfaatan spesies tumbuhan sebagai bahan pakaian adat antara Dayak Kanayatn dan beberapa etnis atau masyarakat di pulau berbeda disebabkan oleh faktor kebudayaan sekitar dan keanekaragaman sumberdaya tumbuhan. Menurut Kusmana \& Hikmat (2015), keanekaragaman tumbuhan antar pulau di Indonesia dipengaruhi oleh garis Wallace dan Weber yang didasari sejarah terbentuknya kepulauan Indonesia. Kalimantan, Jawa, Riau dan Sumatera yang tergolong dalam Dataran Sunda relatif memiliki variasi tumbuhan yang sama, sedangkan Nusa Tenggara tergolong zona flora peralihan (Daerah Wallace) sehingga memiliki keanekaragaman tumbuhan yang cenderung berbeda. Ketersediaan tumbuhan yang beranekaragam pada setiap wilayah dapat menjadi faktor penentu karakter kebudayaan masyarakat di sekitarnya, sehingga semua faktor saling terhubung. Masyarakat Dayak Kanayatn berdasarkan jenis tumbuhan yang dimanfaatkan sebagai bahan pakaian adat dapat dikategorikan berkaitan erat terhadap alam sekitar.

Tumbuhan yang paling banyak digunakan sebagai bahan pakaian dan aksesori dalam seluruh kelengkapan pakaian adat Dayak Kanayatn adalah kulit batang terap (Artocarpus elasticus). A. elasticus adalah jenis tumbuhan yang paling banyak digunakan sebagai penyusun semua komponen utama pakaian, serta merupakan penyusun 13 dari 20 macam komponen pelengkap dan tambahan pada kelengkapan pakaian adat Dayak Kanayatn. Menurut Inayah (2013), masyarakat etnis Dayak Kenyah, Pampang, Samarinda, Kalimantan Timur juga memanfaatkan kulit kapuak (A. elasticus) sebagai bahan pembuatan baju adat $(B a b b)$.

Kulit batang A. elasticus dimanfaatkan karena menghasilkan serat yang kuat tahan lama, lentur, memiliki warna kemerahan, tidak berbau dan ber- 
ukuran lebar. A. elasticus adalah salah satu dari 72 jenis tumbuhan penghasil serat utama yang banyak dimanfaatkan masyarakat Indonesia antara lain sebagai taplak meja, sepatu, dompet, tas dan hasil kerajinan lain (Veriyan et.al., 2019). Berdasarkan informasi responden, masyarakat Dayak Kanayatn memiliki pandangan antropologis tentang A. elasticus, yaitu sebagai pembawa kesejahteraan hidup.

Famili Arecaceae adalah famili yang memiliki spesies paling banyak dimanfaatkan sebagai bahan pakaian adat Dayak Kanayatn yaitu sebanyak 8 spesies (lihat Gambar 2.). Menurut Silvia et.al. (2017), famili Arecaceae banyak dimanfaatkan oleh masyarakat karena dapat tumbuh subur dibeberapa habitat lingkungan, sehingga memiliki ketersediaan tinggi. Bagian tumbuhan anggota famili Arecaceae (akar, batang, daun, buah dan bunga) juga berguna sebagai bahan kerajinan tangan, obatobatan maupun kebutuhan sehari-hari.

Jenis pakaian adat yang menggunakan bahan tumbuhan dari famili Arecaceae adalah komponen aksesori pelengkap dan tambahan pada pakaian, serta tumbuhan secara umum digunakan sebagai bahan anyaman. Menurut Siska et.al. (2015), masyarakat kawasan bukit Kelam Kabupaten Sintang memanfaatkan tumbuhan rotan (Arecaceae) secara khusus sebagai bahan kerajinan bersifat anyaman karena struktur tumbuhan rotan cocok sebagai bahan anyaman. Masyarakat Dayak Kanayatn memanfaatkan banyak spesies dari famili Arecaceae secara khusus tumbuhan rotan karena 12 dari 25 macam kelengkapan pakaian adat yang dibuat merupakan jenis anyaman, sehingga tumbuhan anggota Arecaceae yang dimanfaatkan bermacam jenis.

Tumbuhan yang dimanfaatkan sebagai bahan pembuatan pakaian adat dapat digunakan langsung atau diolah terlebih dahulu. Tumbuhan yang diolah sebelum digunakan berjumlah 23 spesies dan tumbuhan yang digunakan langsung berjumlah 1 spesies.

\section{DAFTAR PUSTAKA}

Alloy, S, Albertus, \& Istiyani, CP, 2008, Mozaik Dayak: Keberagaman Sub Suku dan Bahasa Dayak di Kalimantan Barat, Institut Dayakologi, Pontianak

Andasputra, N, \& Julipin, S, 1997, Mencermati Dayak Kanayatn, Institut Dayakologi, Pontianak
Darmadi, H, 2016, 'Dayak Asal-Usul dan Penyebarannya di Bumi Borneo', Jurnal Pendidikan Sosial, vol. 3, no. 2, hal. 323-334

Dewi, AP, 2016, Etnobotani Dayak Iban-Desa di Kabupaten Sintang Provinsi Kalimantan Barat: Keanekaragaman Jenis dan Anatomi Serat Tumbuhan Anyaman, Skripsi, Institut Pertanian Bogor, Bogor

Fakhrozi, I, 2009, Etnobotani Masyarakat Suku Melayu Tradisional di Sekitar Taman Nasional Bukit Tigapuluh: Studi Kasus di Desa Rantau Langsat, Kecamatan Batang Gangsal, Kabupaten Indragiri Hulu, Provinsi Riau, Skripsi, Institut Pertanian Bogor, Bogor

Florus, P, Djuweng, S, Bamba, J \& Andasputra, N, 2014, Kebudayaan Dayak: Aktualisasi dan Transformasi, Institut Dayakologi, Pontianak, hal. 12-25

Hasanah, U, Linda, R \& Lovadi, I, 2014, 'Pemanfaatan Tumbuhan pada Upacara Adat Tumpang Negeri Suku Melayu di Keraton Ismahayana Landak', Jurnal Protobiont, vol 3, no. 3, hal. 17-24

Ibo, LK \& Arimukti, SD, 2019, 'Studi Etnobotani pada Masyarakat Sub-Etnis Batak Toba di Desa Martoba, Kabupaten Samosir, Sumatera Utara', Prosiding Seminar Nasional Masyarakat Biodiversitas Indonesia, vol. 5, no. 2, hal. 234-241

Inayah, SS, 2013, 'Kesinambungan Identitas Kultural dalam Menjaga Kerukunan Hidup pada Masyarakat Multietnis (Studi Kasus Masyarakat Adat Dayak Pampang Samarinda)', Jurnal Komunikasi Sosial dan Keagamaan, vol. XV, no. 1, hal. 87-89

Irsyad, MN, Jumari \& Murningsih, 2013, 'Studi Etnobotani Masyarakat Desa Sukolilo Kawasan Pegunungan Kendeng Pati Jawa Tengah', Bioma, vol. 15, no. 1, hal. 27-34

Iswandono, E, Zuhud, EAM, Hikmat, A \& Kosmaryandi, N, 2015, 'Pengetahuan Etnobotani Suku Manggarai dan Implikasinya terhadap Pemanfaatan Tumbuhan Hutan di Pegunungan Ruteng, Jurnal Ilmu Pertanian Indonesia, vol. 20, no. 3, hal. 171-181 
Jalung, M, 2015, 'Analisis Semiotika Pakaian Adat Dayak Bahau sebagai Alat Komunikasi Budaya dalam Berinteraksi dengan Masyarakat', eJurnal Ilmu Komunikasi, vol. 3 , no. 4 , hal. 131-132

Kusmana, C \& Hikmat, A, 2015, 'Keanekaragaman Hayati Flora di Indonesia', Jurnal Pengelolaan Sumberdaya Alam dan Lingkungan, vol. 5, no. 2, hal-187-198

Miden, MS, 2014, Dayak Bukit: Tuhan, Manusia, Budaya, Institut Dayakologi, Pontianak

Siska, L, Zainal, S \& Sirait, SM, 2015, 'Etnobotani Rotan sebagai Bahan Kerajinan Anyaman Masyarakat Sekitar Kawasan Taman Wisata Alam Bukit Kelam Kabupaten Sintang', Jurnal Hutan Lestari, vol. 3, no. 4, hal. 496506

Syafitri, FR, Sitawati \& Setyobudi, L, 2014, 'Kajian Etnobotani Masyarakat Desa berdasarkan Kebutuhan Hidup', Jurnal Produksi Tanaman, vol. 2, no. 2, hal. 173

Silvia, Y, Hasanuddin \& Djufri, 2017, 'Etnobotani Tumbuhan Arecaceae di Kecamatan Seulimum', Jurnal Ilmiah Mahasiswa Fakultas Keguruan dan Ilmu Pendidikan Unsyiah, vol. 2, no. 2, hal. 30-43

Suryadarma, I, 2008, Diktat Kuliah Etnobotani, UNY-Press, Yogyakarta

Veriyan, A, Rafdinal \& Linda, R, 2019, 'Kajian Etnobotani Serat Kulit Kayu Kepuak (Artocarpus elasticus Reinw. Ex Blume) pada Suku Dayak Desa' di Desa Kunyai Kecamatan Sungai Tebelian Kabupaten Sintang', Jurnal Protobiont, vol. 8, no. 3, hal. 41-45 